\title{
A experiência do trabalho interdisciplinar da Residência Multiprofissional em Saúde Mental
}

\author{
Ramon Augusto Ferreira de Souza, Beatriz Santana Caçador, Danielle Teles da Cruz, Bianca Maria \\ Ladeira Goulart de Andrade, Adriano Goulart Lara Santos, Adriana Karoline Ottone Veiga
}

\section{Resumo}

O Centro de Atenção Psicossocial da Infância e Juventude (CAPS i) atende crianças e adolescentes portadores de transtornos mentais severos e persistentes. $\mathrm{O}$ atendimento é diário e as atividades oferecidas procuram preservar e fortalecer os laços sociais e familiares do usuário em sua comunidade. Com a chegada da residência multiprofissional em saúde, profissionais médicos, enfermeiros, assistente social e psicólogo foram inseridos a este serviço na modalidade de residentes, complementando e qualificando os trabalhos realizados. Relatar a experiência do trabalho interdisciplinar exercido pelos residentes em saúde mental inseridos no CAPS i em Juiz de Fora, MG. Trata-se de um relato de experiência sobre a prática interdisciplinar desenvolvida por residentes da área da saúde que atuam em um CAPS i no município de Juiz de Fora-MG. Reuniões com usuário e familiares, sala de espera e atividades de educação em saúde, assembleias, acolhimentos, matriciamento, atividades de educação permanente, visita domiciliar, atendimento ambulatorial, bem como a realização de oficinas terapêuticas com usuários que está em atenção diária. Todas essas atividades são discutidas diariamente em reuniões de equipe composta por todos os profissionais do serviço. São articuladas, ainda, ações de cuidado com outros setores, buscando reunir, discutir e compartilhar o cuidado com as escolas, atenção primária a saúde, vara da infância, serviços hospitalar, conselho tutelar, CRAS, CREAS, entre outros. A vivência profissional sustentada na permuta cotidiana de saberes permite o desenvolvimento de uma visão mais global do trabalho de modo que a integralidade do olhar como trabalhador da saúde ganha concretude em nosso modo de ser profissional. Pelas práticas interdisciplinares retroalimentamos nossos esforços na busca por modos de fazer saúde mais coerentes com o paradigma do Sistema Único de Saúde (SUS) e com as primícias humanitárias e ideológicas da Reforma Psiquiátrica no Brasil. O trabalho interdisciplinar permite ainda que reconheçamos com mais propriedade nosso núcleo específico de saber ao mesmo tempo em que nos esforçamos para, de forma partilhada, qualificar e intensificar as ações inscritas nos campos de saber e que, por isso, são responsabilidade de toda equipe. Vivenciar um processo de trabalho pautado na interdisciplinaridade nos permite reconhecer a relação de complementaridade e interdependência de cada saber no campo da saúde de modo que a teoria vai ganhando forma e substância, proporcionando transformações na realidade que categorias profissionais isoladas não seriam capazes de alcançar. Nesta relação de troca de saberes e respeito à autonomia dos diferentes profissionais, observa-se que o diálogo é o dispositivo mais importante de modo a propiciar essa permuta entre as distintas áreas do conhecimento. Essas ações mostraram-se coerentes com os princípios do SUS constituindo-se como práticas que viabilizam a troca de saberes, criando possibilidade de um trabalho interdisciplinar, humanizado e com integralidade. No que tange à gestão e organização do processo de trabalho em saúde, necessário se faz preservar espaços e tempos para que o diálogo entre os profissionais não dependa apenas da vontade daqueles que acreditam nessa perspectiva. Deve, ao contrário, ser parte da estrutura organizacional e delinear o cotidiano das equipes.

Descritores: Enfermagem; Internato e Residência; Equipe de Assistência ao Paciente. 